\title{
INSTRUMENTOS TURÍSTICOS DE COOPERACIÓN PÚBLICO-PRIVADA EN TIEMPOS DE CRISIS: MOTOR DE COMPETITIVIDAD O ESPECIE AMENAZADA?
}

\author{
José Francisco Perles Ribes \\ Ana Belén Ramón-Rodríguez. \\ Universidad Alicante
}

\section{RESUMEN}

La colaboración público-privada se prescribe como elemento fundamental en el proceso de articulación de clusters y en el diseño de una política de promoción de la competitividad turística. Esta política de promoción competitiva se antoja especialmente necesaria en periodos de crisis y depresión económica, pues configuran escenarios de incertidumbre en los que la racionalización de los recursos público-privados y las soluciones creativas podrían sentar las bases del éxito post-crisis. Sin embargo, la subsistencia y viabilidad de los instrumentos de cooperación público-privada pueden verse comprometidos por algunas de las medidas anti-crisis ejercidas a distintos niveles institucionales, afectando al ritmo de recuperación de los destinos turísticos. Este artículo analiza la experiencia del Consorcio Calpe Tourism, un instrumento de cooperación público-privada puesto en marcha en Calpe -un destino turístico de la Costa Blanca- durante la última crisis económica global. La principal conclusión obtenida es que las recientes medidas en materia de estabilidad presupuestaria y racionalidad organizativa implementadas por la Administración dificultan la creación y el funcionamiento de los instrumentos de cooperación público-privada en turismo, precisamente en aquellos momentos en los que la misma podría ser más necesaria.

Palabras clave: Crisis económica, Competitividad, Cooperación público-privada, Consorcio, Calpe.

Recibido: 29 de mayo de 2015

Devuelto para su revisión: 21 de septiembre de 2015

Aceptado: 18 de marzo de 2016

Departamento de Análisis Económico Aplicado. Universidad de Alicante. Apartado 99. 03080 ALICANTE (España).E-mail: jose.perles@ua.es, anar@ua.es 


\title{
Tourist instruments of public-private cooperation on crisis times: competitiveness engine or endangered species?
}

\begin{abstract}
The public-private partnership is basic tool in the process of articulation of tourism clusters and competitiveness. This kind of policy is most necessary in times of economic crisis, where the rationalization of public and private resources and creative solutions could form the basis of successful post-crisis growth period. However, the survival and viability of the instruments of public-private cooperation could be threatened by the anti-crisis measures exercised at various institutional levels. This article analyzes the experience of "Calpe Tourism" Consortium, an instrument of public-private partnership launched in Calpe -a tourist destination placed in the Costa Blanca, Spain- during the last global economic crisis. The main conclusion is that the recent measures on budgetary stability and organizational rationality implemented by Central Government threaten the creation and operation of the tourism partnership, precisely in those moments when it are more necessary.
\end{abstract} Calpe.

Keywords: Economic crises, Competitiveness, Public-private partnership, Consortium,

\section{INTRODUCCIÓN}

Las experiencias de cooperación público-privadas en España no son precisamente novedosas. Las Sociedades de Fomento Turístico y los Centros de Iniciativas Turísticas (CIT) que datan de la primera mitad del siglo XX ya aunaban los esfuerzos de diversos agentes en aras a la promoción del turismo en áreas concretas del territorio nacional, siendo un claro antecedente de las más actuales y sofisticadas Destination Management Organizations (DMO) (Secretaría General de Turismo, 2008:24). Sin embargo, desde la publicación de la obra clásica de Porter (1990) "La Ventaja Competitiva de las Naciones", y bajo la nueva conceptualización de clúster se apreció un redescubrimiento de la cooperación público-privada como elemento de la promoción de la competitividad de los destinos turísticos, siendo precisamente en el plano local, donde se evidencia en mayor medida la necesidad de instituciones de carácter mixto tanto en su participación como en su financiación que reflejen la transversalidad del sector.

Convertido en el objeto básico de análisis de la competitividad de los territorios, el concepto de cluster surge cuando Porter plantea que tratar de explicar la "competitividad" a nivel nacional es responder a una pregunta mal planteada. En vez de eso, el investigador debe concentrar su atención no en el conjunto de la economía, sino en industrias y sectores industriales específicos. Definido por Porter como una concentración geográfica de empresas interconectadas, proveedores especializados, proveedores de servicios, empresas en sectores próximos e instituciones asociadas en ámbitos particulares que compiten pero que también cooperan e instituciones interconectadas en un campo concreto de actividad, el concepto evoca al clásico distrito industrial de Alfred Marshall y guarda importantes semejanzas con los Sistemas Productivos Locales (Garofoli, 1994). 
En un plano turístico, el concepto de clúster se ha vinculado al análisis de la competitividad de los destinos, entendidos como un espacio en el que tiene lugar la confluencia de agentes, iniciativas y experiencias, que acaban moldeando un ente o un lugar como atractivo para la atención del consumo deseado por la demanda de un orden turístico, una vez que se constituye toda una red de empresas especializadas en distintas parcelas de la satisfacción del ocio, a partir de las cuales toma entidad un espacio como ámbito capaz de suministrar uno o más productos turísticos (Monfort, 1999). Aplicada a los destinos así concebidos, la competitividad sería "capacidad de un destino para sostener y expandir su participación en los mercados internacionales y elevar simultáneamente el nivel de vida de su población. Esto exige el incremento de la productividad y, por ende, la incorporación de progreso técnico". Esta competitividad implica tener en cuenta los recursos del territorio, implicar a los agentes e instituciones, integrar a los sectores de actividad en una lógica de innovación y cooperar con otros territorios (Fajnzylber, 1998). Avanzado el tiempo y partiendo de las ideas originales de Porter, han surgido nuevos modelos específicos para el análisis de la competitividad de los destinos turísticos, siendo tal vez el modelo de Calgary (Crouch y Ritchie, 1999) y el modelo integrado de Dywer y Kim (2003) los que mayor grado de reconocimiento han alcanzado. Ambos modelos y otros que han surgido paralelamente otorgan a la cooperación público-privada un papel primordial como motor de la competitividad de los destinos. Desde entonces, innumerables trabajos analizan modelos y experiencias de cooperación público-privada de diversa índole del universo turístico, tanto en la esfera teórica (véase entre otros Bramwell and Lane, 2000; Dredge, 2006; Hall, 2009; Secretaría General de Turismo, 2008; Selin and Chavez, 1995 and March and Wilkinson, 2009); como aplicada (véase entre otros Bové y Guim, 2013; Casellas, 2007; García, 2007; Muñoz y Fuentes, 2013), tratando de establecer las virtudes y las dificultades de cada proceso de cooperación y su influencia sobre la competitividad o sostenibilidad de los destinos. En este trabajo se describe la breve experiencia del Consorcio Calpe Tourism, un instrumento creado en enero de 2012 y disuelto en diciembre de 2014, al objeto de dilucidar las virtudes y dificultades que el mismo ha enfrentado en su misión de promoción de la competitividad de este destino. La principal conclusión obtenida es que algunas medidas anti-crisis, especialmente las dirigidas a racionalizar el funcionamiento de la Administración Local, comprometieron seriamente el funcionamiento operativo de esta entidad hasta el punto de hacerla inviable en los términos iniciales, y obligando a su disolución en un momento crítico para la recuperación de este destino.

\section{LA COOPERACIÓN PÚBLICO-PRIVADA Y LA PROMOCIÓN DE LA COM- PETITIVIDAD TURÍSTICA EN TIEMPOS DE CRISIS}

La cooperación público privada se prescribe como un elemento fundamental en la gestión de los destinos turísticos. Los productos y destinos turísticos actuales implican la participación de una variedad de actores - públicos y privados- que comparten la responsabilidad de planificar, gestionar y comercializar el producto turístico en aras a garantizar su coherencia (Secretaría General de Turismo, 2008:23). Así, se considera que la cooperación entre los sectores público y privado es vital para mejorar la competitividad de los destinos, la rentabilidad de las 
empresas, la satisfacción del turista, reducir el impacto social y medioambiental de la actividad turística y alinear el desarrollo turístico con otras actuaciones prioritarias en el territorio.

En un plano global, las DMO son entidades canalizadoras de los esfuerzos de diferentes actores en el marco de una visión estratégica flexible. Entre sus funciones más habituales destacan: crear un marco favorable para la competitividad del destino, promover la conservación y mejora de los atractivos turísticos, promover la mejora de la calidad del entorno, instalaciones y servicios, impulsar y coordinar esfuerzos para el desarrollo de productos, crear y gestionar una imagen a nivel de destino, liderar y coordinar la investigación de mercado y coordinar la acción promocional con el sector privado (Organización Mundial de Turismo, 2004). El cumplimiento de estas funciones aconseja la existencia de DMO de carácter mixto, público-privadas, bien organizadas, orientadas al mercado y gestionadas por profesionales.

Estas entidades constituyen de esta forma, un elemento fundamental en la configuración de verdaderos clusters turísticos, clusters o agrupaciones que son a su vez, determinantes de la ventaja competitiva sostenible del destino. Aunque el crecimiento sostenido de la demanda turística global en las últimas décadas augura un futuro esperanzador para este sector, el proceso de globalización junto con cambios que tanto por el lado de la demanda (cambios sociodemográficos y turismo internacional cada vez más entendido y exigente, especialmente) como por la vertiente de la oferta (creciente número de destinos, cada vez más modernos) está experimentando la actividad turística, obligan a los destinos a permanecer en constante alerta para seguir manteniendo su competitividad y las cuotas de mercado.

Según Porter (1990), la ventaja competitiva se consigue mediante innovación de procesos y tecnologías, formación y gestión del conocimiento, de forma que resulten diferencias significativas entre diversos competidores. La innovación debe asimilarse por el sistema turístico en su totalidad. La mayor ventaja no se genera con un solo factor innovador, sino cuando el funcionamiento de todo el sistema es único y difícil de imitar dada la mutua dependencia y refuerzo continuo existente entre su componentes. En este ámbito innovador, juega un papel crucial la existencia de entidades que canalicen los esfuerzos públicos y privados en una dirección y objetivo común para el conjunto del destino.

Sin embargo, esta necesidad evidente de un ente de gestión de carácter mixto que coordine y aúne esfuerzos de todos los agentes implicados, no se ha traducido automáticamente en la creación de dichos entes. Por el contrario, existen una serie de barreras (disparidad de objetivos y visiones entre agentes, disparidad de culturas organizativas y capacidades diferenciadas para asumir riesgos financieros) que dificultan tremendamente la puesta en marcha de estas entidades (Secretaría General de Turismo, 2008:24). Además, no hay una fórmula única para establecer un modelo eficaz de colaboración entre los sectores público y privado, si bien, a partir de fuentes apuntadas en el apartado anterior, se desprende que algunos de los factores clave para el éxito de las actividades conjuntas serían el establecimiento de una estructura equilibrada con roles y responsabilidades claras para cada una de las partes; el liderazgo compartido entre el sector público y el privado con objetivos bien definidos, expectativas realistas y una identificación clara de los beneficios para cada sector; la adopción de un enfoque flexible por parte de ambos y la voluntad de entender las necesidades del otro bajo las premisas de sostenibilidad del destino, así como sobre todo contribuir equitativamente en la aportación de recursos. 
En cuanto a la forma concreta que pueden o deben adoptar dichos entes, existe una amplia literatura procedente del propio ámbito turístico, así como de sectores vinculados al mismo. Este es el caso de la que procede de la Gestión comercial de Centros Urbanos, con abundantes referencias a nivel nacional e internacional (véase para una recopilación exhaustiva Generalitat Valenciana, 2004). A modo de ejemplo, un estudio del Consejo de Cámaras de la Comunidad Valenciana identifica para el caso español las siguientes figuras potenciales: asociaciones y fundaciones, agrupaciones de interés económico, sociedades mixtas, consorcios de promoción y gestión, sociedades cooperativas, o sociedades mercantiles (Consejo de Cámaras Comunidad Valenciana, 2007). Cada una de las mismas presenta sus ventajas y sus inconvenientes. De todas estas opciones, y ya en el plano práctico, un estudio llevado a cabo por la Secretaría General de Turismo en 2008 sacaba a relucir que el Consorcio (10.5\%) junto con el Patronato (18.9\%) eran las fórmulas preferidas a nivel local para canalizar la participación privada en el diseño de la política turística. Por el contrario, las fundaciones (7.4\%) o las fórmulas societarias (empresa municipal o mixta) gozaban de menor popularidad para este propósito. (Secretaría General de Turismo, 2008:38). En la mayoría de ocasiones, la gestión del turismo corría a cargo de una concejalía especializada (46.3\%) o una concejalía compartida con otros menesteres (23.2\%) en el caso de los municipios de tamaño más reducido, modelos que no garantizan ni mucho menos la incorporación de la iniciativa privada en el proceso de toma de decisiones.

En principio pudiera parecer que la adopción de una u otra forma jurídica pudiera resultar más o menos neutra para la efectividad de la gestión propuesta. Sin embargo, la reciente realidad ha desmentido dicha neutralidad, puesto que la última Crisis Económica y Financiera Global y la respuesta otorgada a la misma mediante promulgación de la normativa de estabilidad y racionalidad dirigida a entidades locales, comprometió seriamente la viabilidad de los consorcios integrados por entidades locales, que como se ha visto, es una de las formas preferidas por los Ayuntamientos para canalizar la participación privada en turismo. Estas son precisamente las circunstancias a las que se enfrentó el caso que se expone a continuación, el del Consorcio "Calpe Tourism", una entidad creada en el marco de una política integral de competitividad turística que se ha visto abocada a su desaparición por este cambio normativo, tal vez en el momento más inoportuno, en el que podría haberse configurado como un elemento proactivo en las respuestas frente a la crisis que viene sufriendo este destino.

\section{CASO DE ESTUDIO: EL CONSORCIO “CALPE TOURISM" COMO INSTRU- MENTO TURÍSTICO DE COOPERACIÓN PÚBLICO-PRIVADA}

Calpe (Calp, en su denominación oficial) es un destino turístico consolidado de la provincia de Alicante representativo de la dinámica experimentada por el conjunto litoral Mediterráneo español, que ha sido utilizado como unidad de análisis en diversos ámbitos de la competitividad de destinos y el desarrollo local por Perles (2004, 2009, 2010 y 2014). Como muchos destinos de su entorno, este municipio ha alcanzado un alto grado de competitividad en el producto de "sol y playa" familiar, en el que junto a un concepto vacacional, coexiste un fuerte componente residencial, cuyos efectos arrastre 
han propiciado tras de sí el desarrollo de un potente sector inmobiliario, manifestando la terna hostelería-comercio-construcción un peso abrumador como fuente de riqueza y empleo (Perles, 2014).

Aun siendo un producto bien asentado, la excesiva especialización turística en "sol y playa" representa para Calpe, como para otros destinos, una amenaza que lo hace vulnerable frente a fluctuaciones coyunturales de la economía nacional e internacional. La crisis actual y sus repercusiones sobre los indicadores económicos municipales de toda índole -empleo, renta, sostenibilidad financiera del Ayuntamiento, etc.-, han dado fe de ello aconsejando la puesta en marcha de medidas de promoción de la competitividad que reconduzcan la senda del ciclo de vida del destino hacia una fase de rejuvenecimiento en los términos prescritos por Butler (1980). Entre otras muchas medidas anticrisis adoptadas por los responsables municipales (regeneración urbana, diversificación de la oferta a través de la potenciación de eventos locales, etc.), la creación de una entidad de cooperación público privada que aglutinara los esfuerzos de los diversos agentes locales en materia turística se configuraba como una actuación con vocación de permanencia que otorgara carácter estratégico y participado a la política turística del municipio. En este contexto surgió el Consorcio "Calpe Tourism".

El Consorcio "Calpe Tourism", creado en enero de 2012 era una entidad mixta conformada por el Ayuntamiento de Calpe y diversas asociaciones profesionales turísticas de la localidad (la Asociación de Empresarios de Hostelería, la Asociación de Comerciantes, la Asociación de Agencias Inmobiliarias y la Asociación de Oferta Complementaria) al amparo de la Ley 8/2010, de 23 de junio de la Generalitat Valenciana, de Régimen Local de la Comunitat Valenciana que en su art. 108 habilita la creación de consorcios mixtos compuestos por entidades públicas y entidades privadas sin ánimo de lucro que tengan finalidades de interés público concurrente. Era pues una entidad con ámbito de actuación local. De conformidad con sus Estatutos (Diario Oficial de la Generalitat Valenciana ${ }^{\circ}$ 6843 de 20 de agosto de 2012), el Consorcio "Calpe Tourism" tenía por objeto la mejora y promoción del sector turístico de la villa, gozando de personalidad jurídica plena y capacidad de obrar. Tras un primer ejercicio de rodaje, durante el ejercicio 2013 desarrolló sus primeras actuaciones, algunas de amplia repercusión mediática y a finales de 2014, cuando se produjo su disolución, se venía produciendo el proceso de consolidación de la entidad estructurando sus acciones en un Plan de Actuación completamente formalizado.

\subsection{Configuración y estructura del Consorcio Calpe Tourism}

En términos de representatividad, el Consorcio "Calpe Tourism" aglutinaba aproximadamente 150 establecimientos, lo que suponía aproximadamente un 15 por cien de las 853 empresas recogidas por el DIRCE (INE, 2014) en 2013, no existiendo en el municipio otra entidad con tal grado de representatividad. Por lo que respecta al volumen de recursos financieros gestionados por el Consorcio, el montante global entre 2012 y 2014 ascendió a 423.000,00 Euros, con el siguiente desglose: 3.000,00 Euros en 2012; 100.000,00 Euros en 2013 y 320.000,00 Euros en 2014, encontrándose, a finales de ese año la entidad, en pleno proceso de consolidación.

El Programa Anual de Actuaciones de 2014, respaldado por unas líneas estratégicas fundamentadas en los fines del Consorcio consagrados en sus Estatutos, dotaba a las 
mismas de la coherencia necesaria en un entorno turístico tan cambiante como el actual. Dichas líneas estratégicas, así como las actuaciones que desarrollaban cada una de las mismas fueron aprobadas reglamentariamente por los Órganos rectores del Consorcio y elevadas al Ayuntamiento Pleno durante el mes de enero a fin de dar cuenta de las actividades a llevar a cabo y facilitar la cofinanciación de las mismas por dicha entidad.

Las líneas directrices agrupaban las actuaciones en cinco bloques, a saber: investigación y labor consultiva; promoción de la demanda; promoción y diversificación de la oferta; mejora de la competitividad empresarial e información general sobre turismo del municipio. Estas líneas fueron consensuadas por los todos los miembros del Consorcio y representaban un verdadero esfuerzo compartido por todos los agentes implicados en el desarrollo turístico de Calpe.

Pero más allá que las meras consideraciones cuantitativas, lo relevante en este ámbito son los aspectos cualitativos de la cooperación. La puesta en marcha del Consorcio propició la generación de dinámicas de cooperación, tanto entre los propios agentes privados, como entre éstos y el propio Ayuntamiento desconocidas hasta el momento. Así, algunas de las actuaciones llevadas a cabo por el Consorcio complementaron o desarrollaron las llevadas a cabo tradicionalmente por el propio Ayuntamiento. Otras, por el contrario, supusieron verdaderas innovaciones en lo que respecta al sector turístico del municipio. Entre las primeras, la elaboración de estudios o la participación en Ferias de Turismo y la elaboración de material divulgativo eran las más significativas. Desde luego, en ningún caso pretendía el Consorcio sustituir o atribuirse las competencias que el Ayuntamiento tiene en estas materias, sino que su actuación trataba de potenciar y complementar las mismas dotándoles de mayor eficacia en un contexto turístico complicado por la crisis. En este sentido, la labor consultiva del Consorcio alcanzaba un carácter fundamental, pues permitía que las acciones llevadas a cabo fueran compartidas y comprendidas por el sector, algo que no siempre se consigue cuando se carece de la coordinación necesaria. Del mismo modo, la nueva orientación hacia segmentos y mercados emergentes hasta ahora no atendidos por el municipio, se configuraba como un elemento esencial de la política del Consorcio en un marco en el que los mercados más tradicionales mostraban -previo a los efectos de la Primavera Árabe- síntomas de agotamiento y no terminaban de recuperarse de la crisis económica que viene golpeando a muchos orígenes clásicos desde al menos 2007.

En cuanto a las innovaciones, las actuaciones relacionadas con la promoción y diversificación de la oferta y el producto turístico del municipio fueron, tal vez, las más representativas. Hacer de Calpe un verdadero cluster del turismo era un objetivo fundamental del Consorcio en un contexto en el que la demanda turística es cada vez más entendida y exigente; aparecen nuevos competidores tratando de ampliar agresivamente su participación en el mercado turístico y basa su desarrollo en un producto turístico especializado (el sol y playa) que necesita una continua reinvención para seguir siendo atractivo a los potenciales clientes. Del mismo modo, por el Consorcio también se ha pretendido estrechar los lazos con Entidades e Instituciones turísticas de carácter nacional e internacional, tratando de compartir buenas experiencias e información y en su caso, captar fondos para llevar a cabo los ambiciosos propósitos del Consorcio.

Para llevar a cabo este ambicioso proyecto el Consorcio Calpe Tourism contaba con recursos procedentes del propio Consorcio -humanos y financieros- así como de las 
aportaciones de las distintas entidades que lo conforman, especialmente las subvenciones financieras del propio Ayuntamiento de Calpe así como diversas aportaciones "en especie" efectuadas por algunos de los socios de los mismos.

\subsection{Carácter estratégico del Consorcio Calpe Tourism}

Como se ha señalado, las acciones puestas en marcha por el Consorcio se enmarcaron en el desarrollo de unas líneas directrices basadas, a su vez, en los fines establecidos en sus propios Estatutos. Estas directrices (ver Cuadro 1), se agrupaban en cinco grandes áreas (investigación, promoción de la demanda, promoción de la oferta, mejora de la competitividad empresarial y área de información) que intentan reflejar las pautas de mejora competitiva establecidas en los modelos de competitividad que, como el de Porter (1990), han alcanzado mayor éxito.

Estas directrices han cristalizado en diversas acciones, siendo las más relevantes la promoción internacional del destino, concretada en la asistencia a un amplio calendario de ferias de turismo (Oslo, Utrech, Helsinki, Amberes, Dublín, Ghent, París y Moscú, en su mayoría novedosas para este destino), así como una ambiciosa campaña "Inflights" consistente en la contratación de espacios publicitarios durante los meses de marzo, abril, mayo y junio de 2014 en las revistas promocionales de las líneas aéreas de bajo coste más relevantes (Ryanair, Easyjet, Brussels Airlines, Norwegian y Germanwing) con un impacto estimado de 47,6 millones de lectores. Con este mismo enfoque se contrató el espacio publicitario en un paquete de cincuenta mil tarjetas de embarque de Easyjet.

El Consorcio Calpe Tourism, bien de forma directa, bien a través de algunos de sus establecimientos asociados, apoyaron las acciones promocionales organizadas por el propio Ayuntamiento y por el Patronato de Turismo de la Costa Blanca para dar a conocer a Calpe y la Costa Blanca como destino turístico. Dicho apoyo se concretó en la organización de visitas guiadas o el ofrecimiento de cenas y alojamientos en dichos establecimientos en el marco de workshops dirigidos a touroperadores y periodistas de diversas nacionalidades por el Patronato de Turismo de la Costa Blanca. Todas estas acciones se desarrollaron con elevado grado de éxito, alcanzando los objetivos previstos para las mismas.

Por lo que respecta a la promoción nacional, el Consorcio emprendió una Campaña de Promoción Publicitaria bajo el lema "Calpe te espera,..." consistente en la señalización mediante vallas publicitarias, mupis y cartelería bajo el lema mencionado al destino turístico Calpe en las principales accesos/salidas de Madrid y Valencia y otros puntos relevantes de la geografía nacional. Del mismo modo se ubican anuncios sobre Calpe en diversos MUPIS ubicados en la Estación Madrid-Atocha y en los autobuses urbanos de Valencia.

Aparte de las acciones de promoción llevadas a cabo, el Consorcio impulsó diversos eventos locales como la I FIRA DEL PEIX DE CALP I EL ARRÒS DEL SENYORET (una Feria gastronómica que trata de potenciar dos de los principales productos gastronómicos del municipio) y FIRACALP 2014 (otra Feria Gastronómica de amplia aceptación y consolidación en el municipio), así como el refuerzo de los puntos de Información Turística instalados por el Ayuntamiento en zonas de máxima afluencia de la localidad mediante intérpretes rusos, a fin de prestar la debida atención a un mercado con amplio potencial de crecimiento en la localidad. 


\title{
Cuadro 1 \\ DIRECTRICES ESTRATÉGICAS DEL CONSORCIO “CALPE TOURISM”
}

\begin{abstract}
* Área de Investigación y labor consultiva
Profundizar en el conocimiento del sector turístico de la localidad para la aplicación más efectiva de las políticas de Promoción Turística en el municipio promoviendo la realización de estudios e investigaciones sobre el mismo.

Ejercitar la labor consultiva en materia turística en aquellas medidas implementadas por la Concejalía de Turismo del Ayuntamiento de Calpe o cualesquiera otros departamentos cuyas actuaciones puedan tener una incidencia directa o indirecta sobre el sector turístico de Calpe.
\end{abstract}

\section{*}

Promover actividades encaminadas a incrementar la demanda turística, potenciando los mercados internacionales que operan con el destino e intentando abrir nuevos mercados. En concreto se plantea.

- Actuaciones para la consolidación de la marca turística de la localidad.

- Asistencia a Ferias de Promoción Turística

- Elaboración de Campañas de Promoción Turística de Calpe (información y material divulgativo)

\section{* Área de Promoción / Diversificación de la Oferta}

- Promoción de Eventos para captar nuevos segmentos de la demanda turística.

- Gestionar instalaciones y equipamientos de interés turístico de la localidad.

- Puesta en servicio y valorización de potenciales recursos turísticos de la localidad infrautilizados.

\section{*}

- Asesoramiento a empresarios turísticos y potenciales emprendedores.

- Tramitación de ayudas y subvenciones en materia de creación de empresas y autoempleo.

- Fomentar la sostenibilidad ambiental de las actividades turísticas de Calpe

- Fomentar la cultura de la calidad en las empresas turísticas de Calpe.

- Fomentar el uso de las Nuevas Tecnologías de la Información y la Comunicación en las empresas turísticas de Calpe.

- Fomentar la cultura de la competitividad entre el tejido productivo del municipio.

- Potenciar los sectores conexos y de apoyo al sector turístico del municipio.

- Fomentar la conciencia de cluster entre el tejido productivo del municipio.

\section{* Área de Información}

- Potenciar al Consorcio como referencia en materia de información turística de la localidad.

- Creación del Gabinete de Prensa del Consorcio Calpe Tourism.

- Puesta en marcha del Web Site del Consorcio como canal de información del mismo.

- Investigar nuevos canales de información más selectivos "redes sociales" que contribuyan a optimizar los recursos.

Fuente: Plan de Actuación Anual 2014. 
La difusión e implantación del Sistema Integral de Calidad Turísticas en Destinos (SICTED) y puesta en marcha de acciones para la regularización de la oferta de alojamiento constituida por los apartamentos turísticos fueron también acciones llevadas a cabo, con diverso grado de éxito, por el Consorcio al objeto de promover la competitividad turística de Calpe.

En este sentido, y aunque sólo el tiempo confirmará la mayor o menor eficacia de las acciones emprendidas, parece evidente que en el breve plazo de su existencia, el Consorcio Calpe Tourism desempeñó una serie de actuaciones que han tenido un impacto significativo en el principal sector de la economía del municipio y lo que es mejor, ha canalizado la voluntad de cooperación entre los diferentes agentes que conforman el destino contribuyendo a consolidar en Calp un verdadero cluster turístico.

\subsection{El Consorcio "Calpe Tourism" ante la Ley de Racionalidad y Sostenibilidad de la Administración Local}

En 2008 y con origen en Estados Unidos se inició y propagó una profunda crisis económica y financiera (Crisis Económica y Financiera Global) que por mor de las interconexiones económico-financieras de un mundo tremendamente globalizado tuvo un alcance mundial. Esta crisis alcanzó finalmente a España manifestándose con una especial virulencia derivada del estallido de una burbuja inmobiliaria que fue desencadenante de una crisis bancaria sin precedentes (Ortega y Peñalosa, 2013). A fecha actual, todavía quedan patentes importantes secuelas de la crisis (elevada tasa de desempleo, restricción del crédito empresarial, etc.) de las que parece comienza a recuperarse la economía española.

Tras una primera fase de respuesta expansiva frente a la crisis, la reforma del artículo 135 de la Constitución española el 23 de agosto de 2011 (BOE 27 de septiembre de 2011) consagró la estabilidad presupuestaria como principio rector que debe presidir las actuaciones de todas las Administraciones Públicas y constituyó un giro radical en toda regla a la política económica. En desarrollo de este precepto constitucional se aprobó la Ley Orgánica 2/2012, de 27 de abril, de Estabilidad Presupuestaria y Sostenibilidad Financiera, que exigía nuevas adaptaciones de la normativa básica en materia de Administración local para la adecuada aplicación de los principios de estabilidad presupuestaria, sostenibilidad financiera o eficiencia en el uso de los recursos públicos locales. Y fruto de la misma, la Ley 27/2013, de 27 de diciembre, de racionalización y sostenibilidad de la Administración Local desarrolló de forma definitiva el nuevo marco operativo de las entidades locales españolas.

La Ley 27/2013 (BOE 30 de diciembre 2013) que tiene por objeto clarificar las competencias municipales y racionalizar la estructura local en el nuevo contexto de crisis, contiene una disposición final (Disposición final segunda) que modifica la normativa reguladora de los consorcios. En concreto, la citada disposición final introduce una nueva disposición adicional (la vigésima) en la Ley 30/92, de 26 de noviembre de Régimen Jurídico de las Administraciones Públicas y del Procedimiento Administrativo Común, por la que se obligaba a la adscripción de los consorcios a una Administración Pública que se supone dominante en función de diversos criterios como el poder de decisión o financiación del consorcio. Esta adscripción se prevé (punto 3) tanto para el supuesto de 
que el consorcio esté formado única y exclusivamente por entidades públicas, como para el caso en que esté participado por entidades privadas sin ánimo de lucro.

La adscripción a una Administración Pública no sería de mayor relevancia salvo por el hecho de que el punto 4 de la nueva regulación establece que los consorcios estarán sometidos al régimen de presupuestación, contabilidad y control de la Administración pública, sin perjuicio de su sujeción a lo previsto en la Ley 2/2012, de 27 de abril, de Estabilidad Presupuestaria y obligando a la realización de una auditoría de sus cuentas anuales por los órganos competentes de la Administración a la que se adscriba, y asimilando su personal al funcionario o laboral de la administración que corresponda, lo que convierte de facto al consorcio en un departamento más del Órgano Administrativo al que se adscriba. Evidentemente, esto elimina cualquier atisbo de flexibilidad o ventaja que pudiera caracterizar a la gestión del consorcio, respecto de lo que sería la propia gestión directa de la competencia por la entidad a la que se adscriba el mismo, suponiendo una clara amenaza a su viabilidad.

Este nuevo régimen para los consorcios se encuentra en vigor desde el 31 de diciembre de 2013. Desde entonces es aplicable para los nuevos consorcios que se creen. Por su parte, para los ya existentes, la Ley prevé un periodo transitorio de un año -hasta 31 de diciembre de 2014- para la adaptación estatutaria en los términos prescritos. Únicamente aquellos consorcios que constituidos antes de la entrada en vigor de la Ley, que no tengan consideración de Administración Pública a efectos del Sistema Europeo de Cuentas, que se encuentren participados por Entidades Locales y entidades privadas, que no estén incursos en pérdidas durante dos ejercicios consecutivos y que no hayan recibido ayudas públicas en los cinco ejercicios anteriores a la entrada en vigor de la Ley quedan eximidos de tal obligación, rigiéndose por lo que establezcan sus respectivos estatutos (Disposición adicional decimocuarta Ley 27/2013). Probablemente no exista ninguno en todo el país en esta situación.

Ante este nuevo escenario normativo, los responsables de los consorcios debieron plantearse diversas posibilidades. En primer lugar, podían plantear su continuidad en los términos previstos por la nueva normativa de consorcios. Ello suponía evidentemente una duplicidad de esfuerzos y controles respecto de los llevados a cabos por la Administración de adscripción, puesto que obligaría a una contabilidad similar, una intervención similar, las auditorías pertinentes, etc. Por este motivo, la primera opción se antojaba, en principio, poco viable. Una segunda alternativa era optar por la disolución, creando nuevas entidades bajo el paraguas de una forma jurídica que quedara fuera de la regulación prevista para los consorcios. En este sentido, son tal vez las Fundaciones o los Patronatos las alternativas preferidas, como se ha visto en el apartado anterior. Esta podría ser una alternativa temporal, pues cabe esperar que tarde o temprano y en función de los ritmos de recuperación que experimente la economía, la actividad reformadora acabe alcanzando a todo tipo de entes participados por la Administración. Por último, una tercera alternativa era disolver los consorcios y canalizar la participación privada a través de órganos meramente consultivos de la actividad de la Administración competente. Sea cual fuere la alternativa, parece claro que la nueva normativa venía a complicar la supervivencia de una entidad -el consorcio- que era la preferida en la articulación público-privada de la política turística.

Los responsables del Consorcio "Calpe Tourism", ante el nuevo escenario, optaron por su disolución y la creación de una Federación de empresarios que, hoy por hoy, todavía 
dista mucho de ser operativa. Así pues, la aprobación de esta nueva normativa ha dinamitado la dinámica de cooperación público-privada en Calp que propiciaba la existencia del Consorcio. Por todo ello, puede considerarse que la promulgación de la normativa racionalizadora y sin prejuzgar la necesidad o las ventajas que ésta pueda tener en otros muchos aspectos de la gestión económica de la Administración Pública, ha venido a complicar en Calpe la existencia de un instrumento de promoción competitiva del destino, precisamente en el momento en que comenzaba a dar sus frutos y en el que probablemente era más necesario.

\section{CONCLUSIONES}

La competitividad de los destinos turísticos requiere la configuración de verdaderos clusters que favorezcan la articulación de políticas con visión estratégica y canalicen los esfuerzos emprendidos por los diversos agentes que lo conforman bajo una dirección y compromiso común. En la persecución de este objetivo, las entidades que articulan la cooperación público-privada desempeñan un papel primordial. Por ello, y a la par que su grado de implantación y reconocimiento nacional e internacional ha ido creciendo, se han convertido en objeto de estudio teórico-práctico por los académicos del turismo.

En el caso español, los consorcios son una de las formas jurídicas preferidas por los destinos para concretar la constitución de estos entes participativos. Sin embargo, este modelo recurrente de participación se ha visto amenazado. La reciente Crisis Económica y Financiera Global y en concreto una de las respuestas otorgadas a la misma -las medidas de estabilidad y racionalidad administrativa en el ámbito local- han modificado el marco jurídico de los consorcios, complicando tremendamente su continuidad y obligando a los responsables turísticos de los destinos a buscar formas alternativas de cooperación. De este modo, se corre el riesgo de que la búsqueda de la solución a una crisis, muy profunda pero por obligación limitada en el tiempo, acabe por eliminar un instrumento estructural de promoción de la competitividad de los destinos.

El análisis del caso calpino y su consorcio "Calpe Tourism" pone de manifiesto las virtudes de este modelo de cooperación y las incertidumbres y dificultades que entraña su futuro. En la medida en que, como se ha dicho, este es un modelo preferido por muchos mecanismos, las conclusiones obtenidas son generalizables al conjunto de municipios que optan por esta figura como modelo de cooperación.

Es de sobra conocido que las crisis son también periodos de oportunidades. Por ello, desde aquí se reivindica que ante la actual tesitura, los responsables turísticos nacionales aprovechen para definir y articular fórmulas concretas de cooperación público-privada, que con voluntad de permanencia, permitan dar continuidad a esta herramienta básica de promoción de la competitividad de los destinos turísticos.

\section{BIBLIOGRAFÍA}

BRAMWELL, B. y LANE, B. (2000): Tourism Collaboration and Partnerships: Politics, Practice and Sustainability. Channel View Publications. Clevedon, United Kingdom 
BOVÉ, M. y GUIM, M (2013): "La eclosión turística de Barcelona: Política de planificación vs cooperación pública privada. Smart Regions for a Smarter Growth Strategy: New Challenges of the regional policy and potentials cities to overcome a worldwide economic crisis". Oviedo, 21-22 de Noviembre 2013.

BUTLER R. (1980): “The Concept of a Tourist Area Cycle of Evolution: Implications for Management of Resources". Canadian Geographer n 2, pp. 5-12.

CASELLAS, A. (2007): “Gobernabilidad, participación ciudadana y crecimiento económico: adaptaciones locales a estrategias globales". Scripta Nova, Vol XI, n 243, 10 de julio de 2007.

CONSEJO DE CÁMARAS OFICIALES DE COMERCIO, INDUSTRIA Y NAVEGACIÓN DE LA COMUNIDAD VALENCIANA (2007): Gestión de Centros Urbanos. Valencia. Consejo de Cámaras de Oficiales de Comercio, Industria y Navegación de la Comunidad Valenciana.

CROUCH, G.I y RITCHIE J.R. (1999): “Tourism, Competitiveness, and Social Prosperity", Journal of Business Research, $\mathrm{n}^{\circ} 44$, pp. 137-152

DREGDGE, D. (2006): "Policy networks and the local organisation of tourism", Tourism Management, $\mathrm{n}^{\circ} 27$ (2), pp. 269-280.

DWYER, L. y KIM, C. (2003): "Destination competitiveness: determinants and indicators", Current Issues in Tourism, no 6 (5), pp. 369-414.

FAJNZYLBER, F. (1988): “Competitividad internacional, Evolución y Lecciones”, Revista CEPAL n ${ }^{\circ}$ 36. Santiago de Chile.

GARCÍA, M. (2007): "Entidades de planificación y gestión turística a escala local. El caso de las ciudades patrimonio de la humanidad de España”, Cuadernos de Turismo, $\mathrm{n}^{\mathrm{o}} 20$, pp. 79-102.

GAROFOLI, G. (1994): "Los sistemas de pequeñas empresas: un caso paradigmático del Desarrollo Endógeno" en BENKO G. Y LIPIETZ, A. (1994): Las Regiones que ganan. Ed. Alfons el Magnànim.

GENERALITAT VALENCIANA (2004): "I Jornadas Internacionales de Gestión de Centros Urbanos. Generalitat Valenciana”. Conselleria d'Empresa, Universitat i Ciencia.

HALL, C.M. (2009): "Rethinking Collaboration and Partnership: A Public Policy Perspective", Journal of Sustainable Tourism, n 7 (3-4), pp. 274-289.

INE (2014): Indicadores Territoriales. Fichas Locales. www.ine.es.

MARCH, R. y WILKINSON, I. (2009): “Conceptual tools for evaluating tourism partnerships", Tourism Management, $\mathrm{n}^{\mathrm{o}} 30$ (3), pp. 455-462.

MONFORT, V.(1999): Competitividad y factores críticos de éxito en los destinos turísticos mediterráneos: Benidorm y Peñíscola. Tesis Doctoral Universidad de Valencia. Biblioteca Virtual Miguel de Cervantes. Alicante.

MUÑOZ, A. y FUENTES, L. (2013): “La cooperación público privada en el ámbito de la promoción de los destinos. El análisis de redes sociales como propuesta metodológica.", Cuadernos de Turismo, no 31, pp. 199-223.

ORGANIZACIÓN MUNDIAL DEL TURISMO (2004): Cooperación y asociaciones en turismo: una perspectiva mundial. OMT. Madrid, España.

ORTEGA, E. y PEÑALOSA, J. (2013): Algunas reflexiones sobre la economía española tras cinco años de crisis. Documentos Ocasionales del Banco de España, nº 1304. 
PERLES, J. (2004): Turismo, ventaja competitiva y desarrollo local. Tesis Doctoral, Universidad de Alicante. Biblioteca Virtual Miguel de Cervantes.

PERLES, J. (2009): Calpe, causas del éxito turístico residencial. Calpe. Ed. Bubok.

PERLES, J. (2010): "Valorización de productos y reestructuración de destinos turísticos maduros: el papel de las agencias de desarrollo local", Gran Tour: Revista de Investigaciones Turísticas, $\mathrm{n}^{\circ}$ 2, pp. 23-40.

PERLES, J. (2014): “Regeneración urbana, planificación estratégica y gestión del conflicto en destinos turísticos. El caso de Calpe", Pasos, Revista de Turismo y Patrimonio Cultural, no 12 (1), pp. 95-105.

PORTER, M. (1990): The Competitive Advantage of Nations. Free Press. New York

SECRETARÍA GENERAL DE TURISMO (2008): Modelos de gestión turística local. Principios y Prácticas. Madrid. Secretaría General de Turismo y Federación Española de Municipios y Provincias.

SELIN, S. y CHAVEZ, D. (1995): "Developing an evolutionary tourism partnership model", Annals of Tourism Research, $\mathrm{n}^{\mathrm{o}} 22$ (4), pp. 844-856

ZAPATA, M.J. y HALL, M. (2012): "Public-private collaboration in the tourism sector: balancing legitimacy and effectiveness in local tourism partnerships. The Spanish case", Journal of Policy Research in Tourism, Leisure and Events, n 4 (1), pp. 61-83. 